\title{
Non-invasive imaging techniques in assessing non-alcoholic fatty liver disease: a current status of available methods
}

\author{
Lăpădat $\mathrm{AM}^{*}$, Jianu IR**, Ungureanu BS**, Florescu LM*, Gheonea DI ${ }^{\star \star}$, Sovaila $\mathrm{S}^{\star \star *}$, Gheonea IA* \\ *Radiology and Medical Imaging, University of Medicine and Pharmacy, Craiova, Romania \\ ${ }^{* *}$ Research Center of Gastroenterology and Hepatology, University of Medicine and Pharmacy, Craiova, Romania \\ ${ }^{* *}$ Centre Hospitalier de Sedan, France and Internist.ro Clinic, Brasov, Romania \\ Correspondence to: Silvia Sovaila, MD, PhD, \\ Centre Hospitalier de Sedan, France and Internist.ro Clinic, Brasov, Romania, \\ Mobile phone: +40733 911 513, E-mail: sovaila.silvia@internist.com \\ Received: September 24th, 2016 - Accepted: December 14th, 2016
}

\begin{abstract}
Non-alcoholic fatty liver disease (NAFLD) is an ailment affecting and increasing a number of people worldwide diagnosed via noninvasive imaging techniques, at a time when a minimum harm caused by medical procedures is rightfully emphasized, more sought after, than ever before. Liver steatosis should not be taken lightly even if its evolution is largely benign as it has the potential to develop into non-alcoholic steatohepatitis (NASH) or even more concerning, hepatic cirrhosis, and hepatocellular carcinoma (HCC). Traditionally, liver biopsy has been the standard for diagnosing this particular liver disease, but nowadays, a consistent number of imagistic methods are available for diagnosing hepatosteatosis and choosing the one appropriate to the clinical context is the key. Although different in sensitivity and specificity when it comes to determining the hepatic fat fraction (FF), these imaging techniques possessing a diverse availability, operating difficulty, cost, and reproducibility are invaluable to any modern physician. Ultrasonography (US), computed tomography (CT), magnetic resonance imaging (MRI), elastography, and spectroscopy will be discussed in order to lay out the advantages and disadvantages of their diagnostic potential and application.

Although imagistics has given physicians a valuable insight into the means of managing NAFLD, the current methods are far from perfect, but given the time, they will surely be improved and the use of liver biopsy will be completely removed.
\end{abstract}

Keywords: non-alcoholic fatty liver disease, non-invasive imaging techniques, hepatosteatosis

\section{Introduction}

Non-alcoholic fatty liver disease (NAFLD) represents a hepatic lipid accumulation at an intra-cellular level, over time [1]. With more than $20 \%$ to $30 \%$ of the world population being affected, NAFLD oversees a wide range of hepatic disorders and is frequently associated with diabetes mellitus, dyslipidemia, obesity and hypertension, joining up to form a metabolic syndrome [24]. The disease may present as an incidental finding in patients with a persistent abnormal level of hepatic enzymes or during an abdominal ultrasound. Even though NAFLD may have a benign evolution, in $5-6 \%$ of the cases, it might lead to non-alcoholic steatohepatitis (NASH) [5] and to the development of even more serious conditions $[4,6,7]$, such as cirrhosis and hepatocellular carcinoma (HCC).

Confirming the presence of NAFLD and controlling the disease's evolution is conditioned by the assessment of the liver's fat content. A quick diagnosis is imperative, as steatosis has only one documented management method which consists of lifestyle changes focusing on nutrition and exercise [5]. Liver biopsy is known to be the trademark for the diagnosis and classification standards of NAFLD. However, this procedure should be used only when there is a lack of more beneficial alternatives, due to its invasiveness and potential for error upon the retrieval of the tissue samples. Secondly, hepatosteatosis is a heterogenic disease, and may be difficult to pathologically lead to a diagnosis, because the biopsy samples only reflect a small portion of the hepatic cellular architecture [8-10]. Even so, the pathological examinations of cross-liver sections and the semi-quantitative estimation of the percentage of hepatic parenchyma cells containing fat droplets is widely used as a conventional mean of determining the degree of hepatosteatosis $[5,10]$.

Currently, there is a justified high emphasis on causing as little discomfort as possible, with a global focus on less invasive techniques, with minimal risks to the patient's wellbeing. Striving to overcome the risks of invasive procedures, imaging techniques are on the spotlight in diagnosing and assessing liver steatosis. Several methods have received an extensive attention 
and have proven to be worthy of a future evaluation such as ultrasonography (US), elastography, computed tomography (CT), magnetic resonance imaging (MRI), magnetic resonance spectroscopy (MRS) and chemical shift imaging (CSI). With such a large demand for quality screening, diagnosis and treatment assessment for patients suffering from hepatic steatosis, imaging methods seem to be the future direction of managing NAFLD. Therefore, we tried to review the current standings of the NALFD non-invasive diagnosis and management from the available methods to more advanced techniques (Table 1).

Table 1. Current available methods and availability for liver steatosis assessment

$\begin{array}{ccccccccc}\text { Technique Availability } & \begin{array}{c}\text { Patient } \\ \text { risk }\end{array} & \begin{array}{c}\text { Procedure } \\ \text { duration }\end{array} & \begin{array}{c}\text { Operating } \\ \text { difficulty }\end{array} & \begin{array}{c}\text { Procedure } \\ \text { cost }\end{array} & \begin{array}{c}\text { Accuracy in } \\ \text { determining } \\ \text { hepatic lipid } \\ \text { content }\end{array} & \begin{array}{c}\text { Reproducibili } \\ \text { ty }\end{array} \\ \text { US } & \text { High } & \text { None } & \text { Low } & \text { Low } & \text { Low } & \begin{array}{c}\text { Low to mild } \\ \text { hepatosteatosis }\end{array} \\ \text { CT } & \text { High } & \begin{array}{c}\text { Possible } \\ \text { radiation } \\ \text { hazard }\end{array} & \text { Fair } & \text { Low } & \text { Fair } & \begin{array}{c}\text { Low to mild } \\ \text { hepatosteatosis }\end{array} & \text { Fair } \\ \text { MRI } & \text { Fair } & \text { None } & \text { High } & \text { Fair } & \text { High } & \text { High } & \text { High } \\ \text { MRS } & \text { Low } & \text { None } & \text { High } & \text { High } & \text { High } & \text { High } & \text { High }\end{array}$

\section{Ultrasonography (US)}

Usually, US is the first frontier in diagnosing NAFLD in patients with elevated hepatic enzymes. Even though it may not be as precise as liver biopsy, US surely has stronger advantages being a non-invasive technique, with no radiation, available in extremely high numbers across the medical centers across the world and with low costs [11-13]. Normal hepatic tissue is considered homogeneous in echotexture, similar to the right kidney's cortex and the spleen's parenchyma. Through the intracellular build-up of fat droplets, NAFLD on US imaging is identified by a higher echogenicity than the other two reference organs (Fig. 1).

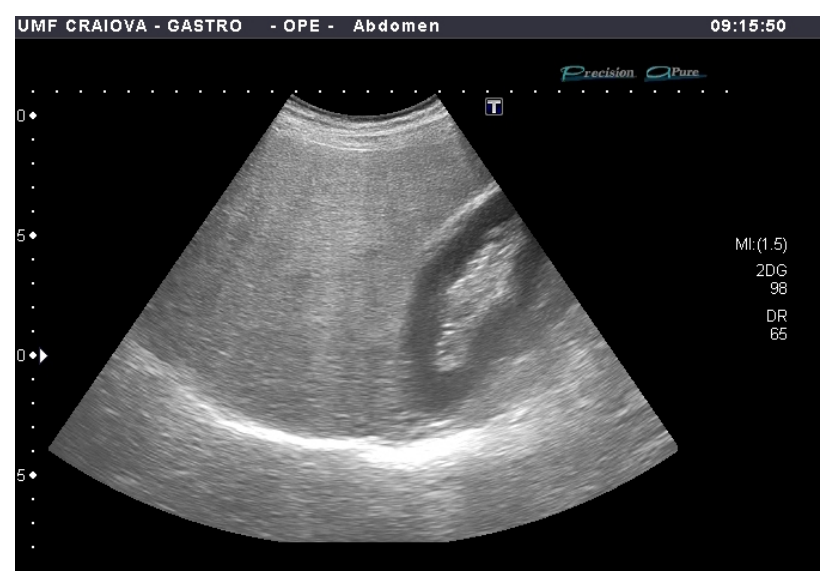

Fig. 1 B-mode ultrasound showing hyperechoic liver comparing with the kidney parenchyma and posterior attenuation of the deep liver parenchyma in the context of hepatic steatosis
Moreover, portal or hepatic vein vascular blurring and hepatomegaly may accompany hepatic steatosis [11,14-16]. For a proper US exam, a 2-5 MHz convex probe should be used. Usually, there are three levels of hepatosteatosis utilized, ranging from mild to severe [1620] and in case of optimal gain settings, they accurately describe the echogenicity features (Table 2). Considering the percentage of hepatocytes affected by liver steatosis the US is used for grading (Table 3).

Table 2. Characteristics and classification of hepatic steatosis Hepatic echogenicity Level of hepatosteatosis

$\begin{array}{cc}\text { Normal } & 0 \\ \text { Simply increased } & 1 \text { (mild) } \\ \text { Echogenic walls of portal } & 2 \text { (moderate) } \\ \text { vein branches obscured by } & \\ \text { liver echogenicity } & \\ \text { Diaphragmatic outline } & 3 \text { (severe) } \\ \text { obscured by liver } & \\ \text { echogenicity } & \end{array}$

Table 3. Grading of hepatic steatosis grade 0 (normal) $=$ up to $10 \%$ of the cells affected; grade 1 (mild) $=10-33 \%$ of the cells affected; grade 2 (moderate) $=34-66 \%$ of the cells affected; grade 3 (severe) $=\geq 67 \%$ of the cells affected;

However, US has several limitations, especially when trying to detect mild levels of fatty liver disease or when trying to distinguish hepatic fibrosis from steatosis [16-21]. Several studies have demonstrated a 60\% sensitivity and $80 \%$ specificity for detecting NAFLD $[13,19,22-26]$. Even though US is relatively easy to perform and interpret, some limitations may be 
encountered: a quantitative assessment is not performed, when lower than $20 \%$ steatosis may not be detected $[11,27,28]$, high inaccuracies are related to obese patients and the fact that it is operator dependent may interfere with the results. Therefore, additional research is required to raise US to clinical and technical peaks. This is the moment transient elastography and acoustic radiation force impulse elastography come into play, as they can be integrated into the standard USG system adding to the utility of US.

\section{Sonoelastography}

Transient elastography (FibroScan, EchoSens, Paris, France) and acoustic radiation force impulse (ARFI) elastography are important tools used to determine the extent of the liver stiffness. Elastography is one of the few imaging methods capable of determining and characterizing liver steatosis and fibrosis $[29,30]$. FibroScan translates the degree of fat infiltration of the hepatic parenchyma into the liver stiffness. The higher the tissue rigidity, the faster the sheer wave is propagated [31-33]. CAP (Controlled Attenuation Parameter) is used to quantify liver steatosis. This technique is coupled with the FibroScan and measures ultrasound wave attenuation, which change depending mainly on the viscosity of the medium through which the waves travel. On the other hand, ARFI is used to examine the elasticity of a certain anatomical area during real-time $B$ mode imaging, with the help of a region-of-interest cursor. It is similar to FibroScan [34]. Real-time elastography (RTE) represents the other imaging technique, and provides realtime measurements of liver stiffness [35]. It uses a B-mode machine, incorporating the elastography software into the conventional ultrasound scanner. The relative elasticity of the tissue is calculated and displayed as real-time color images simultaneously with the B-mode images. The disadvantages of this method are the body mass index, the penetration is limited to 3-4 cm and also operator dependency [36]. New ultrasound machines have included real time analysis software for the quantitative assessment of the stiffness by using hue histograms. This partially eliminates the human bias (Fig. 2).

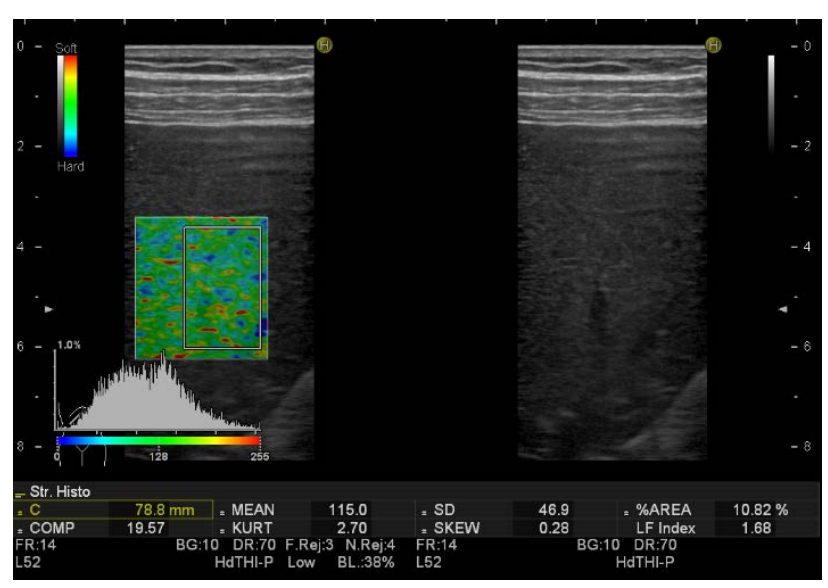

Fig. 2 Quantitative (mean hue histogram = 115) and qualitative (soft appearance of the liver parenchyma) realtime elastography revealing hepatic steatosis

\section{Computed tomography (CT)}

A non-operator dependent, fast, but more harmful alternative to US in diagnosing NAFLD is the CT. It involves subjecting the patient to radiation, but radiation exposure can be kept at a minimum by using low-dose protocols. Due to factors $[11,14,37]$ related to scan timing and contrast material enhanced CT is less used in favor of unenhanced $\mathrm{CT}$.

NAFLD is determined with a high efficiency by using an unenhanced $\mathrm{CT}$ as it evaluates the liver attenuation quantitatively (Fig. 3).

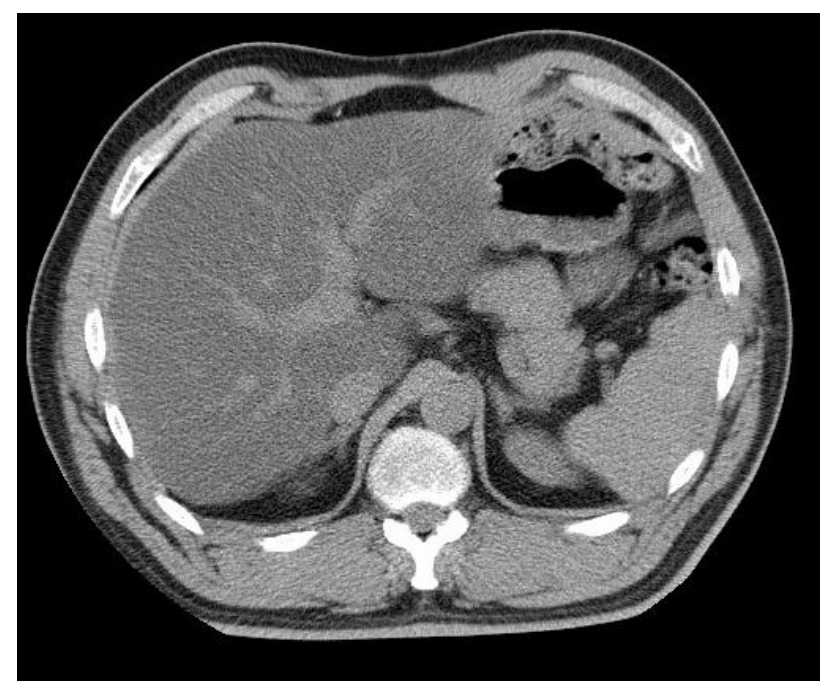

Fig. 316 slices-unenhanced CT, which depicts lower attenuation values of liver tissue comparing with spleen

Using the aforementioned low-dose protocols, an unenhanced CT (implementing a 10-mm section thickness with a collimation of $128 \times 0.625$ at $80 \mathrm{kV}$ and $100 \mathrm{mAs}$ with modulated dose) measures liver attenuation by utilizing randomly selected circularly shaped regions of interest (ROls) ranging from 20 to $40 \mathrm{~mm}^{2}$, which may be selected from both lobes (Fig. 4).

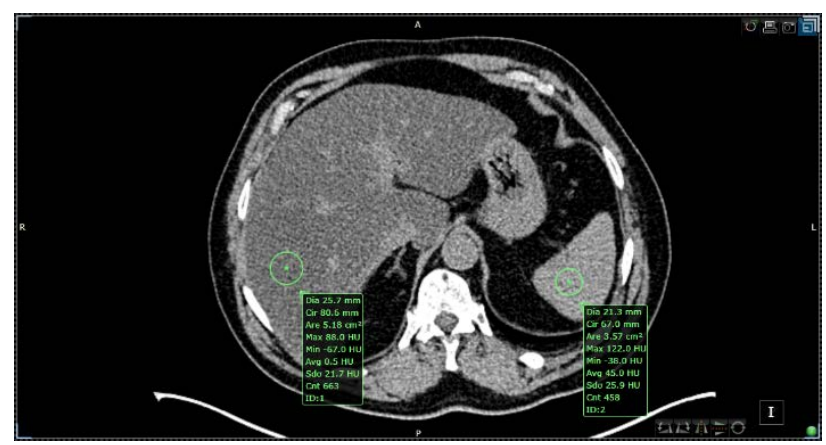

Fig. 4 Liver steatosis semi-quantitative assessment with Siemens 16-slices-unenhanced CT with the region of interest (ROI) placement in the liver and spleen parenchyma 
The CT evaluation of non-alcoholic fatty liver disease depends on the value of Hounsfield Units (HUs), which represents the attenuation parameters of hepatic parenchyma $[12,14,15,38]$. The normal hepatic tissue has an attenuation value of around 50-65 HU, 8-10 HU higher than a normal spleen [11]. Fatty liver assessment may be performed by determining the difference between the attenuation values of liver and spleen, calculating the ratio of absolute measurements in contrast with the liver attenuation index [38-40]. The lower the attenuation is on the unenhanced CT, the higher the liver lipid content. As a result, the CT method is known to be able to diagnose moderate and severe hepatosteatosis with a specificity of $100 \%$ and a sensitivity of $82 \%$ [38]. Additionally, liver attenuation values of less than $40 \mathrm{HU}$ or a liver-to-spleen attenuation difference $>10 \mathrm{HU}$ confirm the presence of liver steatosis $[13,39,41]$. Therefore, when the hepatic attenuation is lower than $48 \mathrm{HU}$, hepatosteatosis can be diagnosed with good accuracy. Studies have shown that liver lipid infiltration of about $30 \%$ is translated into a liver attenuation value of $40 \mathrm{HU}$ and that the unenhanced CT diagnosis methods have a more than favorable precision in determining the degree of build-up fat inside the liver. Additionally, this confirmed that the higher liver attenuation values reflect a healthier liver. It has also been suggested that a liver-to-spleen ratio lower than 1 could sometimes predict lipid infiltration $[13,39,40]$. It can be stated that when hepatic fat build-up is involved, there is a decrease in liver attenuation at low energy levels, which suggests that the tube potential causes an increase in fat attenuation. Regardless of the method used, it is vital to remember that all CT applications imply radiation exposure and just as US, CT has difficulties in picking up mild steatosis. Furthermore, the addition of other pathologies characterized by substance liver accumulation, influence the attenuation of hepatic parenchyma [42]. The administration of chemotherapeutics such as methotrexate or amiodarone, other hepatic diseases $[\mathbf{1 1}, \mathbf{2 9}, \mathbf{4 3}]$ including cirrhosis, acute hepatitis or acute toxic hepatic injury also modify the attenuation of the liver's parenchyma.

\section{Magnetic Resonance Imaging}

This particular non-invasive and free of the potential radiation hazard, the MRI, has benefited from numerous technological advancements along the years, but it is still relatively expensive and time consuming. The recent progress in the MRI field has made easier a precise quantitative evaluation of liver steatosis. What makes lipids stand out from the abundant water molecules at a voxel (a value that represents a finite volume in a 3D space) level is a highly specific element, enabled by the main magnetic field $[2,44,45]$, known as the resonance frequency offset.

Today, a large array of techniques come to aid both the physician and the patient (Chemical shift imaging, MR spectroscopy, and MR elastography) and allow the characterization of fatty liver and quantify the fat signal fraction (FSF) or fat fraction (FF), representing liver triglyceride concentration $[45,46]$. In the case of modern MR imaging, this biomarker stands for the density of hydrogen protons from fat, normalized from the total hydrogen proton density from all mobile proton species. The value of the FF is modified depending on noise bias, the fat's spectral complexity, T1 bias, T2* decay and eddy currents [47-51]. When the fat fraction values are at the upper or lower extremes (close to $0 \%$ or $100 \%$ ), water-fat separation inaccuracies appear, but all this is part of how the eddy currents affect the relative phase of the acquired echoes when using multi-echo acquisitions. This can be avoided through the usage of a magnitude fitting method, in order to mitigate the effects of eddy currents by removing their phase shifts [50].

\section{Chemical Shift Imaging (CSI)}

The idea of CSI originated from the frequency difference between water and the dominant resonance of methylene within fat and it implies acquisitioning T1weighted IP (in-phase) and OP (opposed-phase) images. This MRI method is known to have a sensitivity and specificity of $90 \%$, respectively $91 \%$ [51]. It is based on the fact that lipids and water transverse magnetization vectors develop a phase difference during echo time (TE) and under opposed-phase (OP) conditions results in a shortening of the overall length of the magnetization vector [52-54]. Measurements for this technique are usually done at values of $-220 \mathrm{~Hz}$ and 1,5-3 Tesla (T). The level of lipid accumulation is directly related with the amount of signal loss in OP imaging while the signal intensity (SI) for the affected liver is boosted during the IP condition, obtaining a means to determine hepatic fat fraction $[55,56]$. Hepatic FF can be determined by calculating the difference between the loss of SI in OP images and SI increase in IP images. This can be simply expressed by using the relationship:

$$
F F=\left[\left(S l_{i p}-S l_{o p}\right) / 2 S l_{i p}\right] \times 100,
$$

where $S l_{i p}$ is the liver to spleen signal intensity measured in in-phase images and $\mathrm{Sl}_{\text {op }}$ is the liver to spleen $\mathrm{SI}$ in opposed-phase images. Only congruent and acquired within the same breath-hold sets of IP and OP images must be used to obtain a precise FF. Following this method, the hepatic fat content dissemination throughout the liver parenchyma may be estimated while using the obtained FF hepatic maps.

Gradient-echo (GRE) imaging is a type of CSI that involves the patient holding his breath is the most commonly used technique for the determination of the hepatic FSF. Unfortunately, abnormal levels of liver iron, as in hemochromatosis, affects fat fraction when using GRE. It is important to mention that conventional MRI methods only allow the detection of signals from free water and triglycerides. In order to obtain optimal results, rigorous post-processing, proper calibration, and an intricate signal combination from the phased-array coils, spectral modeling alongside $\mathrm{T} 2$ correction is necessary. 


\section{The Dixon Technique}

Explained for the first time in 1984 by WT Dixon, this technique initially produced an unacceptable amount of artefacts because of the limited MRI technology at that time [53]. Today, this method has been greatly improved and is based on chemical shift, having as a main purpose the uniform fat suppression. Some of the advantages of using this method are better uniformity of the fat signal suppression, fewer artefacts produced, compatible with many other sequence types and weightings, single acquisition images can be provided with and without fat suppression and it is able to quantify the amount of fat (Fig. 5).
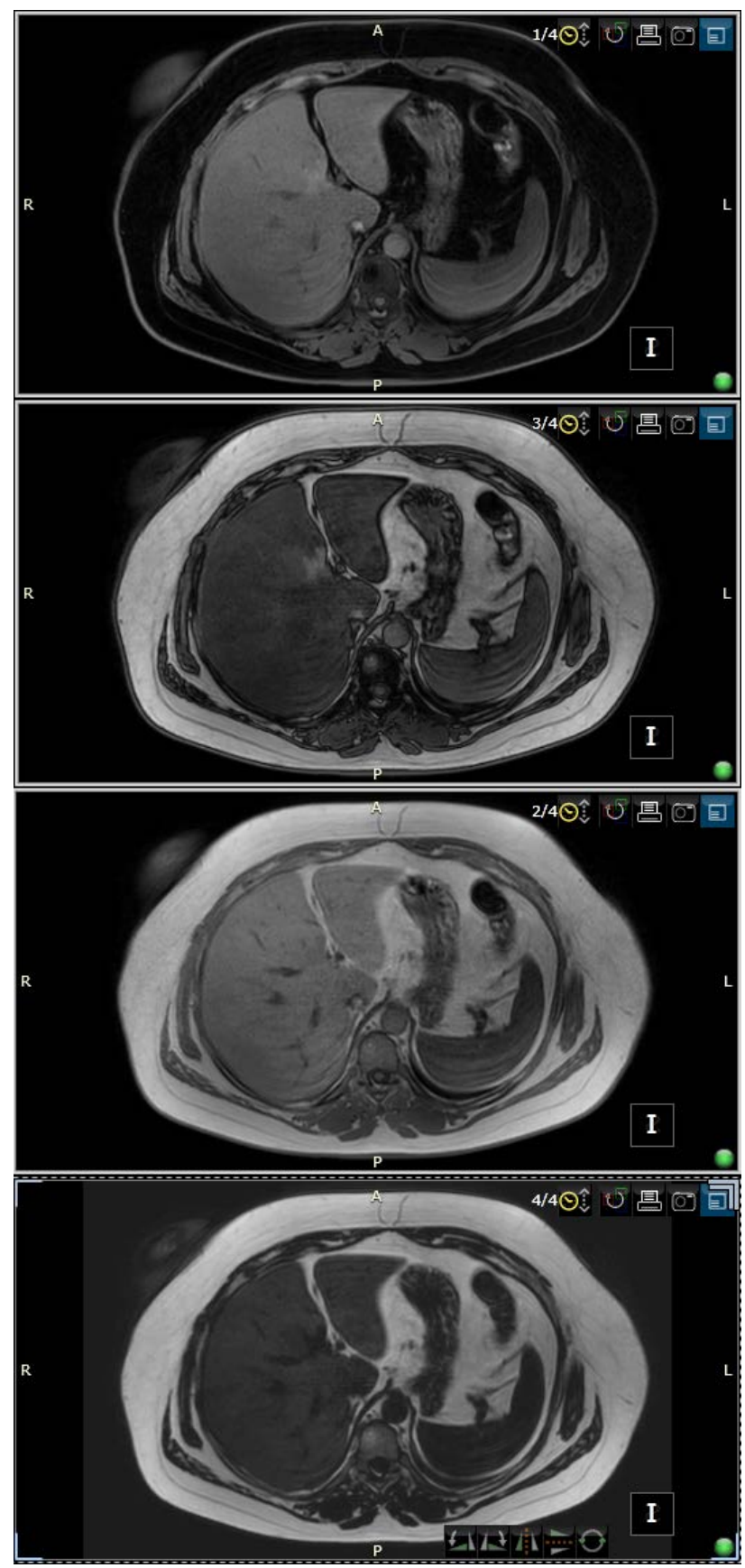

Fig. 5 3T MRI, multi-echo DIXON-All breath hold sequences consisting in T1-weighted sequence, in-phase T1 weighted sequence, out-of-phase T1 weighted sequence and fat specific sequence qualitatively assessing liver steatosis
One of the main characteristics that the Dixon technique has is based on the different rates at which the water and fat molecules are processed. Therefore, the molecules will be found alternating between in-phase and opposed phase. Having said this, the result of running a Dixon technique would be four sequences, after both alternative phases have been acquired [57]. While the water only image can only be utilized as a fat suppressed image, the fat only image can then be added to the other sequences of different weightings in order to obtain fat suppression and also for quantification in certain scenarios. However, this method has some limitations when it comes to waterfat interchanging, that are determined by the magnetic field.

\section{Magnetic Resonance Spectroscopy (MRS)}

In recent years, MR spectroscopy has been considered a reference standard of non-invasiveness when assessing the triglyceride liver content, but not even this method is deprived of complications and is not applicable in every clinical context. MRS is useful for determining the intensity increase of lipid peaks when liver steatosis is present at parts per million (ppm) with values between 1.9 and 2.3, 1.1 and 1.5, and 0.8 and 1.1 $[44,58-65]$. In the case of in vivo MR spectroscopy, single$\mathrm{T} 2^{*}$ correction has been able to produce acceptable results [66], showing an elevated intensity of lipid resonance peak in patients with fatty liver disease.

The collection of spectra for signal fat-fraction estimation requires a proper acquisition technique in order to estimate the fat. Usually, a single voxel is manually placed into the liver parenchyma avoiding liver edges, large vessels, and bile ducts. Through two particular single-voxel MR spectroscopy (SVS) techniques, the FF can be estimated with excellent accuracy: stimulatedecho acquisition (STEAM) and point-resolved spectroscopy (PRESS) $[62,64,67,68]$. The breathing motion must be taken into account because it further complicates conventional MR spectroscopy approaches, while the signal averaging may be lowered or cut out, permitting breath-hold acquisitions. Hepatic water and fat spectra is viewed in high detail and in a direct manner all thanks to high-resolution MR spectroscopy acquisitions. The spectroscopy in the liver is limited to single-voxel acquisition (Fig. 6).

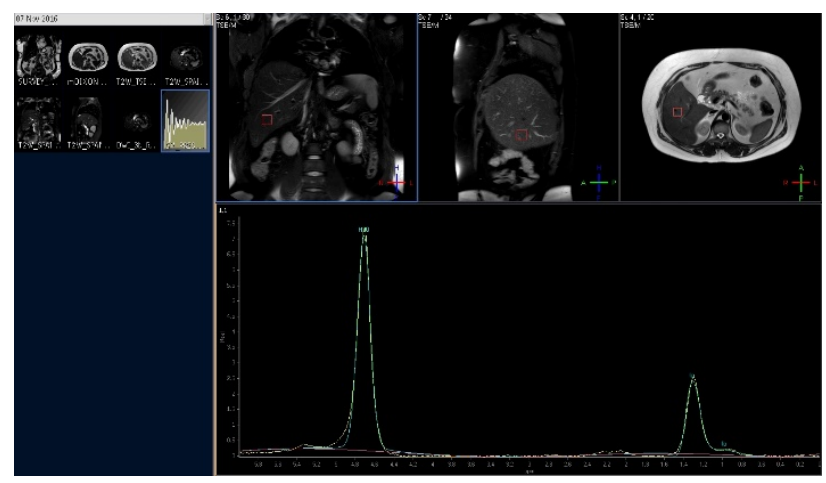

Fig. 6 3T single voxel MR spectroscopy quantitatively evaluating liver steatosis with a manually calculated fatfraction of $42,21 \%$ representing moderate steatosis 
Multivoxel spectroscopy permits the coverage of larger volumes in the liver but the large volume reduces the quality of the shim and spectra and also leads to breathing induced artefacts.

Every single metabolite benefits from spectral area measurements that can be associated and linked to determine the total fat fraction. The process precision comes from assessing the FF in relation to water. The area of lipid (average peak 1.3) and water (average peak 4.67) need to be recorded to calculate FF. Then, the fat signal is calculated as the fat signal divided by the sum of the water and fat peaks areas with dynamic range results from $0-100 \%$.

However, conventional MR spectroscopy has its disadvantages. For high-resolution readings of small volumes, a process of signal averaging for an optimal signal-to-noise ratio (SNR) and lipid peak separation must be applied to the acquisition. Analyzing the spectra is a less attractive aspect of the MR spectroscopy, as extracting water and lipid quantities requires sophisticated processing software. A spectral-frequency representation is obtained after post-processing and the total ROI lipids are estimated while treating multiple lipid spectra as one element. This approach was proven effective in vivo and in phantoms $[5,12,13,45]$. High-resolution liver MR spectroscopy has proven that lipid spectrum consists of at least six distinct observable triglyceride proton resonances. Thus, the total hepatic lipid fraction is formed by multiple fat spectra that have a role within the MR signal model.

The empirical evidence offers the values of distinct chemical shifts, leaving the individual's absolute magnitude differ from sample to sample. Fortunately, calibration is used to obtain relative amplitude values in the case of lipids related to hepatosteatosis [69], reducing the difficulty of the complex signal equation. Furthermore, in most cases, attributing a single $\mathrm{T} 2^{\star}$ value for all lipid resonances is acceptable, but field inhomogeneity effects are to be expected. However, each lipid resonance can be given a specific $\mathrm{T2}^{*}$ value [70] for better field homogeneity.

The proton density-weighted estimation of water and lipid reflects the metabolite concentration properly, when the correction of relaxation effects and of other system and field effects is executed correctly.
Although independent from confounders such as glycogen, fibrosis, and hemochromatosis, MRS requires patient co-operation. Despite all these, it provides a good degree of precision when it comes to the quantitative analysis of the hepatic FF.

With all these available MR imaging techniques, MR spectroscopy must be mentioned as an invaluable becoming tool in the assessment of NAFLD.

\section{Conclusions}

In conclusion, NAFLD is an ailment to be reckoned with, as its increase at a global scale is worrisome. Hepatic FF assessing by using non-invasive methods such as US, CT, MRI and MRS has given physicians great insight into NAFLD. The diversity of current imaging, non-invasive alternatives of quantifying the degree of hepatic steatosis is a breath of fresh air for both physicians and patients. Each alternative has advantages and disadvantages and choosing the appropriate one must be done keeping in mind the patient's best interest. To sum up, there are pros and cons of the most frequently used imagistic methods to determine the degree of fat content in the hepatic parenchyma.

The necessity for precise, non-invasive, and reproducible imagistic methods for estimating the lipid content of the liver is extremely high as patients need to be evaluated periodically and efficiently assessed in order to determine the treatment results and the lifestyle changes used to manage hepatosteatosis. This high demand will surely result in great innovation in the field of non-invasive imagining, improving the current imagistic methods for evaluating NAFLD and hopefully will even completely replace the use of liver biopsy.

\section{Acknowledgments}

This work was supported from the research grant entitled "Complex-imaging evaluation of liver steatosis in patient with combined Sylimarin, Phyllanthus niruri and choline treatment", contract number 1334/ 17.12.2015.

\section{References}

1. Adams LA, Lindor KD. Nonalcoholic fatty liver disease. Ann Epidemiol. 2007; 17:863-9.

2. Idilman IS, Aniktar H, Idilman $R$, Kabacam G, Savas B, Elhan A, Celik A, 4. Bahar K, Karcaaltincaba M. Hepatic steatosis: quantification by proton density fat fraction with MR imaging versus liver biopsy. Radiology. 2013; 267:767-75.

3. Matteoni CA, Younossi ZM, Gramlich T, Boparai N, Liu YC, McCullough AJ.
Nonalcoholic fatty liver disease: a $5 . \quad$ Glen J, Floros L, Day C, Pryke R. Nonspectrum of clinical and pathological alcoholic fatty liver disease (NAFLD): severity. Gastroenterology. 1999; summary of NICE guidance. BMJ. 2016; 116:1413-9. 354.

Vernon G, Baranova A, Younossi ZM. 6. Bosch FX, Ribes J, Díaz M, Cléries R. Systematic review: the epidemiology and natural history of non-alcoholic fatty liver disease and non-alcoholic steatohepatitis in adults. Aliment Pharmacol Ther. 2011; 7. 34:274-85
Primary liver cancer: worldwide incidence and trends. Gastroenterology. 2004; 127(5 Suppl 1):S5-s16.

. Center MM, Jemal A. International trends in liver cancer incidence rates. Cancer 
Epidemiol Biomarkers Prev. 2011; 19. Joseph AE, Saverymuttu SH, al-Sam S, 31. Yoneda M, Suzuki K, Kato S, Fujita K 20:2362-8.

8. Bondini S, Kleiner DE, Goodman ZD, Gramlich T, Younossi ZM. Pathologic assessment of non-alcoholic fatty liver disease. Clin Liver Dis. 2007; 11:17-23.

9. Janiec DJ, Jacobson ER, Freeth $A$, Spaulding L, Blaszyk H. Histologic variation of grade and stage of nonalcoholic fatty liver disease in liver biopsies. Obes Surg. 2005; 15:497-501.

10. Ratziu V, Charlotte F, Heurtier A, 21. Mathiesen UL, Franzén LE, Aselius H, Gombert S, Giral P, Bruckert E, Grimaldi A, Capron F, Poynard T. Sampling variability of liver biopsy in nonalcoholic fatty liver disease. Gastroenterology. 2005; 128:1898-906.

11. Chen $\mathrm{CL}$, Cheng YF, Yu CY, Ou HY, Tsang LL, Huang TL, Chen TY, Concejero A, Wang CC, Wang SH, Lin $\mathrm{TS}$, Liu YW, Yang $\mathrm{CH}$, Yong $\mathrm{CC}$, Chiu KW, Jawan B, Eng HL, Chan SC, Sharr WW, Lo CM, Tamura S, Sugawara $Y$, Kokudo N, Lee KW, Yi NJ, Suh KS, Moon DB, Lee SG, Ahn CS, Huang S, Kim KH, Ha TY, Song GW, Jung DH, Park GC, Namkoong JM, Park HW, Park YH, Park CS, Sung KB, Ko GY, Gwon DI, Kaido T, Ogawa K, Fujimoto Y, Ito T, Toniyama K, Mori A, Ogura $Y$, Uemoto S, Yap AQ, Lin YH, Liu CY, Chiang YC, Lin CC, Shin M, Joh JW, Kabiling C, Hu TH, Kang SH, Jung BH, Choi YR. Living donor liver transplantation: the Asian perspective. Transplantation. 2014; 97 Suppl 8:S3.

12. de Alwis NM, Anstee QM, Day CP. How to Diagnose Nonalcoholic Fatty Liver 25. Disease. Dig Dis. 2016; 34 Suppl 1:19-26.

13. Singh D, Das CJ, Baruah MP. Imaging of non alcoholic fatty liver disease: A road less travelled. Indian J Endocrinol Metab. 26 2013; 17:990-5

14. Lee SS, Park SH. Radiologic evaluation of nonalcoholic fatty liver disease. World J Gastroenterol. 2014; 20:7392-402.

15. Obika M, Noguchi H. Diagnosis and evaluation of nonalcoholic fatty liver 27. lijima $H$, Moriyasu F, Tsuchiya K, disease. Exp Diabetes Res. 2012; Suzuki S, Yoshida M, Shimizu M, 2012:145754.

16. Saadeh S, Younossi ZM, Remer EM, Gramlich T, Ong JP, Hurley M, Mullen KD, Cooper JN, Sheridan MJ. The utility of radiological imaging in nonalcoholic fatty liver disease. Gastroenterology. 2002; $123: 745-50$

17. Tsuchiya H, Ebata $Y$, Sakabe T, Hama S, Kogure K, Shiota G. High-fat, highfructose diet induces hepatic iron overload via a hepcidin-independent mechanism prior to the onset of liver steatosis and insulin resistance in mice. Metabolism. 2013; 62:62-9.

18. Acikel M, Sunay S, Koplay M, Gündoğdu F, Karakelleoğlu S. Evaluation of ultrasonographic fatty liver 30. Polyzos SA, Mantzoros CS. Necessity and severity of coronary atherosclerosis, and obesity in patients undergoing coronary angiography. Anadolu Kardiyol Derg. 2009; 9:273-9. Cook MG, Maxwell JD. Comparison of liver histology with ultrasonography in assessing diffuse parenchymal liver disease. Clin Radiol. 1991; 43:26-31.

20. Needleman L, Kurtz $A B$, Rifkin MD, Cooper HS, Pasto ME, Goldberg BB. Sonography of diffuse benign liver disease: accuracy of pattern recognition and grading. AJR Am J Roentgenol. 1986; 146:1011-5.

Resjö M, Jacobsson L, Foberg U, Frydén A, Bodemar G. Increased liver echogenicity at ultrasound examination reflects degree of steatosis but not of fibrosis in asymptomatic patients with mild/moderate abnormalities of liver transaminases. Dig Liver Dis. 2002; 34:516-22.

2. Debongnie JC, Pauls C, Fievez M, Wibin $\mathbf{E}$. Prospective evaluation of the diagnostic accuracy of liver ultrasonography. Gut. 1981; 22:130-5.

23. Hamaguchi M, Kojima T, Itoh Y, Harano Y, Fujii K, Nakajima T, Kato T, Takeda N, Okuda J, Ida K, Kawahito Y, Yoshikawa T, Okanoue T. The severity of ultrasonographic findings in nonalcoholic fatty liver disease reflects the metabolic syndrome and visceral fat accumulation. Am J Gastroenterol. 2007; 102:2708-15.

24. Hamer OW, Aguirre DA, Casola G, Lavine JE, Woenckhaus M, Sirlin CB. Fatty liver: imaging patterns and pitfalls. Radiographics. 2006; 26:1637-53.

5. Saverymuttu SH, Joseph AE, Maxwell 37. JD. Ultrasound scanning in the detection of hepatic fibrosis and steatosis. Br Med J (Clin Res Ed). 1986; 292:13-5.

26. Webb $M$, Yeshua $H$, Zelber-Sagi $S$, Santo E, Brazowski E, Halpern Z, Oren R. Diagnostic value of a computerized hepatorenal index for sonographic 38 . quantification of liver steatosis. AJR Am J Roentgenol. 2009; 192:909-14.

Suzuki S, Yoshida M, Shimizu M, Decrease in accumulation of ultrasound contrast microbubbles in non-alcoholic steatohepatitis. Hepatol Res. 2007; 37:722-30.

28. Khov N, Sharma A, Riley TR. Bedside ultrasound in the diagnosis of nonalcoholic fatty liver disease. World J Gastroenterol. 2014; 20:6821-5

29. Park YS, Park SH, Lee SS, Kim DY, Shin YM, Lee W, Lee SG, Yu ES. Biopsyproven nonsteatotic liver in adults: estimation of reference range for difference in attenuation between the liver and the spleen at nonenhanced CT. Radiology. 2011; 258:760-6.

Polyzos SA, Mantzoros CS. Necessity nonalcoholic fatty liver disease. Metabolism. 2014; 63:161-7. Nozaki Y, Hosono K, Saito S, Nakajima A. Nonalcoholic fatty liver disease: USbased acoustic radiation force impulse elastography. Radiology. 2010; 256:640-7.

2. Sandrin L, Fourquet B, Hasquenoph JM, Yon S, Fournier C, Mal F, Christidis C, Ziol M, Poulet B, Kazemi F, Beaugrand M, Palau R. Transient elastography: a new noninvasive method for assessment of hepatic fibrosis. Ultrasound Med Biol. 2003; 29:1705-13.

33. Talwalkar JA, Kurtz DM, Schoenleber SJ, West CP, Montori VM. Ultrasoundbased transient elastography for the detection of hepatic fibrosis: systematic review and meta-analysis. Clin Gastroenterol Hepatol. 2007; 5:1214-20.

34. Chan WK, Nik Mustapha NR, Mahadeva S. Controlled attenuation parameter for the detection and quantification of hepatic steatosis in nonalcoholic fatty liver disease. J Gastroenterol Hepatol. 2014; 29:1470-6.

5. Orlacchio A, Bolacchi F, Antonicoli M, Coco I, Costanzo E, Tosti D, Francioso S, Angelico M, Simonetti G. Liver elasticity in NASH patients evaluated with real-time elastography (RTE). Ultrasound Med Biol. 2012; 38:537-44.

36. Gheonea DI, Săftoiu $A$, Ciurea $T$, Gorunescu F, lordache S, Popescu GL, Belciug S, Gorunescu M, Săndulescu L. Real-time sono-elastography in the diagnosis of diffuse liver diseases. World Journal of Gastroenterology: WJG. 2010; 16:1720-1726.

. Johnston RJ, Stamm ER, Lewin JM, Hendrick RE, Archer PG. Diagnosis of fatty infiltration of the liver on contrast enhanced CT: limitations of liver-minusspleen attenuation difference measurements. Abdom Imaging. 1998; 23:409-15.

38. Kodama $\mathrm{Y}, \mathrm{Ng} \mathrm{CS}, \mathrm{Wu} \mathrm{TT}$, Ayers GD, Curley SA, Abdalla EK, Vauthey JN, Charnsangavej C. Comparison of $\mathrm{CT}$ methods for determining the fat content of the liver. AJR Am J Roentgenol. 2007; 188:1307-12.

39. Park SH, Kim PN, Kim KW, Lee SW, Yoon SE, Park SW, Ha HK, Lee MG, Hwang S, Lee SG, Yu ES, Cho EY. Macrovesicular hepatic steatosis in living liver donors: use of $\mathrm{CT}$ for quantitative and qualitative assessment. Radiology. 2006; 239:105-12.

40. Ricci C, Longo R, Gioulis E, Bosco M, Pollesello $P$, Masutti $F$, Crocè LS, Paoletti S, de Bernard B, Tiribelli C, Dalla Palma L. Noninvasive in vivo quantitative assessment of fat content in human liver. J Hepatol. 1997; 27:108-13.

41. Schwenzer NF, Springer F, Schraml C, Stefan N, Machann J, Schick F. Noninvasive assessment and quantification of liver steatosis by ultrasound, computed tomography and magnetic resonance. J Hepatol. 2009; 51:433-45. 
42. Limanond P, Raman SS, Lassman C, Sayre J, Ghobrial RM, Busuttil RW, Saab S, Lu DS. Macrovesicular hepatic steatosis in living related liver donors: correlation between $\mathrm{CT}$ and histologic findings. Radiology. 2004; 230:276-80.

43. Pickhardt PJ, Park SH, Hahn L, Lee SG, Bae KT, Yu ES. Specificity of unenhanced CT for non-invasive diagnosis of hepatic steatosis: implications for the investigation of the natural history of incidental steatosis. Eur Radiol. 2012; 22:1075-82.

44. Machann J, Thamer C, Schnoedt B, Stefan N, Haring HU, Claussen CD, Fritsche A, Schick F. Hepatic lipid accumulation in healthy subjects: a comparative study using spectral fatselective MRI and volume-localized $1 \mathrm{H}$ MR spectroscopy. Magn Reson Med. 2006; 55:913-7.

45. Raptis DA, Fischer MA, Graf R, Nanz D, 56. Weber A, Moritz W, Tian Y, Oberkofler $\mathrm{CE}$, Clavien PA. MRI: the new reference standard in quantifying hepatic steatosis?. Gut. 2012; 61:117-27.

46. Reeder SB, Robson PM, Yu $\mathrm{H}$, Shimakawa A, Hines CD, McKenzie CA, Brittain JH. Quantification of hepatic steatosis with MRI: the effects of accurate fat spectral modeling. J Magn Reson Imaging. 2009; 29:1332-9.

47. Bydder M, Yokoo T, Hamilton G, 5 Middleton MS, Chavez AD, Schwimmer JB, Lavine JE, Sirlin CB. Relaxation effects in the quantification of fat using gradient echo imaging. Magn Reson Imaging. 2008; 26:347-59.

48. Liu CY, McKenzie CA, Yu H, Brittain JH, Reeder SB. Fat quantification with IDEAL gradient echo imaging: correction of bias from $T(1)$ and noise. Magn Reson Med. 2007; 58:354-64.

49. Yu H, McKenzie CA, Shimakawa A, Vu AT, Brau AC, Beatty PJ, Pineda AR, Brittain JH, Reeder SB. Multiecho reconstruction for simultaneous water-fat decomposition and $\mathrm{T}^{*}$ estimation. J Magn Reson Imaging. 2007; 26:1153-61.

50. $\mathrm{Yu} H$, Shimakawa $A$, Hines $C D$, McKenzie CA, Hamilton G, Sirlin CB, Brittain JH, Reeder SB. Combination of complex-based and magnitude-based multiecho water-fat separation for accurate quantification of fat-fraction. Magn Reson Med. 2011; 66:199-206.

51. Yu H, Shimakawa A, McKenzie CA, Brodsky E, Brittain JH, Reeder SB. Multiecho water-fat separation and 62 simultaneous $\mathrm{R}^{*}$ estimation with multifrequency fat spectrum modeling Magn Reson Med. 2008; 60:1122-34.

52. Blatter DD, Morris AH, Ailion DC, Cutillo AG, Case TA. Asymmetric spin echo sequences. A simple new method for 63. obtaining NMR $1 \mathrm{H}$ spectral images. Invest Radiol. 1985; 20:845-53.

53. Dixon WT. Simple proton spectroscopic imaging. Radiology. 1984; 153:189-94.

54. Sepponen RE, Sipponen JT, Tanttu JI. A method for chemical shift imaging: demonstration of bone marrow involvement with proton chemical shift imaging. J Comput Assist Tomogr. 1984; 8:585-7.

55. Kreft BP, Tanimoto A, Baba Y, Zhao L, Chen J, Middleton MS, Compton CC, Finn JP, Stark DD. Diagnosis of fatty liver with MR imaging. J Magn Reson Imaging. 1992; 2:463-71.

Qayyum A, Goh JS, Kakar S, Yeh BM, Merriman RB, Coakley FV. Accuracy of liver fat quantification at MR imaging: comparison of out-of-phase gradient-echo and fat-saturated fast spin-echo techniques--initial experience. Radiology. 2005; 237:507-11.

57. Banerjee AK. Practical guide to abdominal and pelvic MRI. 2nd edition. The British Journal of Radiology. 2012; 85:291-291.

Johnson NA, Walton DW, Sachinwalla $\mathrm{T}$, Thompson $\mathrm{CH}$, Smith K, Ruell PA, 67. Stannard SR, George J. Noninvasive assessment of hepatic lipid composition: Advancing understanding and management of fatty liver disorders. Hepatology. 2008; 47:1513-23.

59. Kawamitsu H, Kaji Y, Ohara T, Sugimura K. Feasibility of quantitative intrahepatic lipid imaging applied to the magnetic resonance dual gradient echo sequence. Magn Reson Med Sci. 2003; 2:47-50.

60. Kim H, Taksali SE, Dufour S, Befroy D, Goodman TR, Petersen KF, Shulman GI, Caprio S, Constable RT. Comparative MR study of hepatic fat quantification using single-voxel proton spectroscopy, two-point dixon and threepoint IDEAL. Magn Reson Med. 2008; 59:521-7.

61. Mehta SR, Thomas EL, Bell JD, Johnston DG, Taylor-Robinson SD. Non-invasive means of measuring hepatic fat content. World J Gastroenterol. 2008; 14:3476-83.

62. Pineda N, Sharma P, Xu Q, Hu X, Vos M, Martin DR. Measurement of hepatic lipid: high-speed T2-corrected multiecho acquisition at 1H MR spectroscopy--a rapid and accurate technique. Radiology. 2009; 252:568-76.

63. Szczepaniak LS, Babcock EE, Schick F, Dobbins RL, Garg A, Burns DK, McGarry JD, Stein DT. Measurement of intracellular triglyceride stores by $\mathrm{H}$ spectroscopy: validation in vivo. Am J Physiol. 1999; 276:E977-89.

64. Thomsen, C., Becker U, Winkler K, Christoffersen $P$, Jensen $M$, Henriksen O. Quantification of liver fat using magnetic resonance spectroscopy. Magn Reson Imaging. 1994; 12:487-95.

5. Yokoo T, Bydder M, Hamilton G, Middleton MS, Gamst AC, Wolfson T, Hassanein T, Patton HM, Lavine JE, Schwimmer JB, Sirlin CB. Nonalcoholic fatty liver disease: diagnostic and fatgrading accuracy of low-flip-angle multiecho gradient-recalled-echo MR imaging at 1.5 T. Radiology. 2009; 251:67-76.

66. Meisamy $S$, Hines CD, Hamilton G, Sirlin CB, McKenzie CA, Yu H, Brittain $\mathrm{JH}$, Reeder SB. Quantification of hepatic steatosis with T1-independent, T2corrected MR imaging with spectral modeling of fat: blinded comparison with MR spectroscopy. Radiology. 2011; 258:767-75.

67. Hamilton G, Middleton MS, Bydder M, Yokoo $T$, Schwimmer JB, Kono $Y$, Patton HM, Lavine JE, Sirlin CB. Effect of PRESS and STEAM sequences on magnetic resonance spectroscopic liver fat quantification. J Magn Reson Imaging. 2009; 30:145-52

68. Sharma P, Martin DR, Pineda N, Xu Q, Vos M, Anania F, Hu X. Quantitative analysis of T2-correction in single-voxel magnetic resonance spectroscopy of hepatic lipid fraction. J Magn Reson Imaging. 2009; 29:629-35.

9. Hamilton G, Yokoo T, Bydder M, Cruite I, Schroeder ME, Sirlin CB, Middleton MS. In vivo characterization of the liver fat ${ }^{1} \mathrm{H}$ MR spectrum. NMR Biomed. 2011; 24:784-90.

70. Brix G, Heiland S, Bellemann ME, Koch T, Lorenz WJ. MR imaging of fatcontaining tissues: valuation of two quantitative imaging techniques in comparison with localized proton spectroscopy. Magn Reson Imaging. 1993; 11:977-91. 